\title{
Níveis de triptofano digestível em rações para suínos machos castrados de alto potencial genético na fase dos 97 aos $125 \mathrm{~kg}^{1}$
}

\author{
Adriana Aparecida Pereira ${ }^{2}$, Juarez Lopes Donzele ${ }^{3}$, Rita Flávia Miranda de Oliveira ${ }^{3}$, Márvio \\ Lobão Teixeira de Abreu ${ }^{4}$, Francisco Carlos de Oliveira Silva ${ }^{5}$, Mariana dos Santos Martins ${ }^{6}$
}

\author{
${ }^{1}$ Projeto financiado pelo CNPq e apoiado pela AJINOMOTO-BIOLATINA. \\ 2 Pós-graduação em Zootecnia - UFV. \\ 3 Departamento de Zootecnia - UFV. \\ ${ }^{4}$ Pós-doutorado DZO/UFV. \\ 5 EPAMIG. \\ ${ }^{6}$ Curso de graduação em Zootecnia - UFV. Bolsista PIBIC.
}

RESUMO - Foram utilizados 80 suínos machos castrados, híbridos comerciais de alto potencial genético para deposição de carne na carcaça, para avaliar o efeito dos níveis de triptofano digestível para suínos dos 97,0 $\pm 2,81$ aos $125,0 \pm 3,31 \mathrm{~kg}$. O delineamento experimental foi de blocos ao acaso com cinco tratamentos $(0,124 ; 0,133 ; 0,142 ; 0,151$ e $0,160 \%$ de triptofano digestível, correspondentes às relações de 16,$5 ; 17,7 ; 18,9 ; 20,1$ e 21,3\% com a lisina digestível, cada um com oito repetições de dois animais. As rações e a água foram fornecidas à vontade. O ganho de peso melhorou de forma quadrática até o nível estimado de $0,144 \%$ de triptofano digestível. Os níveis de triptofano digestível não influenciaram o consumo de ração, a conversão alimentar, a espessura de toucinho e o rendimento de carne, mas afetaram de forma linear crescente o consumo de triptofano digestível. O nível de $0,144 \%$ de triptofano digestível, correspondente a uma relação com a lisina digestível de 19,2\%, proporciona melhor resposta de ganho de peso em suínos machos castrados de alto potencial genético para deposição de carne na carcaça na fase dos 97,0 aos $125,0 \mathrm{~kg}$.

Palavras-chave: aminoácidos, carcaça, desempenho, terminação

\section{Dietary digestible tryptophan levels for barrows with high genetic potential in the phase from 97 to $125 \mathrm{~kg}$}

\begin{abstract}
Eighty barrows, commercial hybrids of high genetic potential for lean meat deposition in the carcass, were used to evaluate the effect digestible tryptophan levels for pigs from $97.0 \pm 2.81$ to $125.0 \pm 3.31 \mathrm{~kg}$. A randomized experimental block design was used, with five treatments $(0.124 ; 0.133 ; 0.142,0.151$ and $0.160 \%$ of digestible tryptophan, corresponding to digestible lysine ratio of $16.5,17.7,18.9,20.1$ and 21.3\%), each one with eight replications of two animals. Diets and water were supplied ad libitum. Weight gain quadraticaly improved up to the estimated level of $0.144 \%$ of digestible tryptophan. Digestible tryptophan levels did not influence feed intake, feed:gain ratio, backfat thickness and lean meat yield. However, treatments linearly affected digestible tryptophan intake. Digestible tryptophan level of $0.144 \%$, corresponding to a digestible lysine ratio of $19.2 \%$ provides the best weight gain in barrows with high genetic potential for lean meat deposition in the carcass in the phase from 97.0 to $125.0 \mathrm{~kg}$.
\end{abstract}

Key Words: amino acids, carcass, finishing, performance

\section{Introdução}

Atualmente, os suínos têm sido abatidos com maior peso visando a otimização do uso de equipamentos e da mão-de-obra, além do aumento do rendimento da carcaça e dos principais cortes industriais. $\mathrm{O}$ abate de suínos mais pesados também pode ser vantajoso, uma vez que permite aumentar a produção de carne sem alterar o número de matrizes.
A alta demanda dos consumidores e das indústrias por carne suína com pouca gordura tem incentivado grandes empresas suinícolas a investir no máximo crescimento cárneo dos suínos por meio da nutrição. Nutricionistas têm procurado utilizar os conceitos da proteína ideal e de digestibilidade de aminoácidos para obter balanço adequado de aminoácidos. Assim, todos os aminoácidos necessários à perfeita manutenção e ao crescimento da espécie seriam fornecidos sem deficiências, reduzindo os excessos

Este artigo foi recebido em 18/6/2007 e aprovado em 7/5/2008.

Correspondências devem ser enviadas donzele@ufv.br. 
e melhorando a retenção de nitrogênio (Baker \& Chung, 1992).

Entre outros aminoácidos essenciais, o triptofano destaca-se porque, além de participar da síntese protéica, é precursor de serotonina, que está relacionada ao estímulo da ingestão de alimento (Henry et al., 1992) e à diminuição do estresse que antecede o abate. $\mathrm{O}$ efeito negativo da deficiência de triptofano na ingestão voluntária de alimento e no desempenho de crescimento de suínos em terminação está relacionado principalmente à concentração de proteína bruta na ração, uma vez que o transporte de triptofano pelas membranas celulares, tanto no intestino como no cérebro, compete com o transporte dos aminoácidos neutros de cadeia longa (AANCL). Assim, haverá menor quantidade de triptofano metabolizado em serotonina e, conseqüentemente, menor ingestão de alimento.

Tanto as concentrações de triptofano, como o nível de proteína bruta da ração, resultam em interação com o sexo. As fêmeas, em comparação aos machos castrados, são mais sensíveis à deficiência de triptofano, que influencia a ingestão voluntária de alimento (Henry et al., 1992).

Apesar da importância do triptofano para o desenvolvimento e o comportamento dos suínos, são escassas as informações disponíveis sobre as exigências nutricionais de suínos abatidos com pesos mais elevados. Assim, este estudo foi realizado para avaliar os efeitos de níveis de triptofano digestível, utilizando o conceito de proteína ideal, sobre o desempenho e a composição da carcaça de suínos machos castrados pesados (97,0 a 125,0 kg).

\section{Material e Métodos}

O experimento foi conduzido na Granja de Suínos da Fazenda Experimental Vale do Piranga, de propriedade da EPAMIG, localizada no município de Oratórios, Minas Gerais.

Foram utilizados 80 suínos machos castrados, híbridos comerciais de alto potencial genético para deposição de carne com peso inicial de 97,0 $\pm 2,81 \mathrm{~kg}$, distribuídos em delineamento experimental de blocos ao acaso, com cinco tratamentos $(0,124 ; 0,133 ; 0,142 ; 0,151$ e $0,160 \%$ de triptofano digestível, correspondentes às relações com a lisina digestível de 16,$5 ; 17,7 ; 18,9 ; 20,1$ e $21,3 \%$, respectivamente), cada um com oito repetições de dois animais. $\mathrm{Na}$ distribuição dos animais em cada bloco, adotou-se como critério o peso dos animais.

Os animais foram alojados em baias providas de comedouros semi-automáticos e bebedouros do tipo chupeta, em galpão de alvenaria com piso de concreto e cobertura de telhas de amianto.
As rações experimentais (Tabela 1) foram formuladas para serem isoenergéticas e isoprotéicas, à base de milho e farelo de soja e suplementadas com minerais e vitaminas para atender às exigências nutricionais dos animais, segundo Rostagno et al. (2005), exceto de triptofano. Os níveis de triptofano digestível avaliados foram obtidos por meio da inclusão de L-triptofano em substituição ao ácido glutâmico, com base no equivalente protéico, em quantidades ajustadas com adição do amido.

A fim de assegurar que nenhum outro aminoácido ficasse limitante na ração, a relação entre lisina digestível e os demais aminoácidos essenciais digestíveis ficaram no mínimo dois pontos percentuais acima daquela preconizada por Fuller (1996) para suínos dos 50,0 aos 110,0 kg alimentados com rações formuladas segundo o conceito da proteína ideal.

Tabela 1 - Composição das rações experimentais

\begin{tabular}{|c|c|c|c|c|c|}
\hline \multirow[t]{2}{*}{ Ingrediente $(\%)$} & \multicolumn{5}{|c|}{ Nível de triptofano digestível (\%) } \\
\hline & 0,124 & 0,133 & 0,142 & 0,151 & 0,160 \\
\hline Milho & 83,76 & 83,76 & 83,76 & 83,76 & 83,76 \\
\hline Farelo de soja & 13,80 & 13,80 & 13,80 & 13,80 & 13,80 \\
\hline Fosfato bicálcico & 0,309 & 0,309 & 0,309 & 0,309 & 0,309 \\
\hline Calcário & 0,792 & 0,792 & 0,792 & 0,792 & 0,792 \\
\hline Ácido glutâmico & 0,100 & 0,087 & 0,074 & 0,060 & 0,047 \\
\hline Amido & 0,052 & 0,056 & 0,060 & 0,064 & 0,068 \\
\hline L-lisina. $\mathrm{HCl}(78,5 \%)$ & 0,312 & 0,312 & 0,312 & 0,312 & 0,312 \\
\hline DL-metionina (99\%) & 0,077 & 0,077 & 0,077 & 0,077 & 0,077 \\
\hline L-treonina $(98,5 \%)$ & 0,111 & 0,111 & 0,111 & 0,111 & 0,111 \\
\hline L-triptofano $(99 \%)$ & 0,000 & 0,009 & 0,018 & 0,028 & 0,037 \\
\hline Premix vitamínico ${ }^{1}$ & 0,150 & 0,150 & 0,150 & 0,150 & 0,150 \\
\hline Premix mineral $^{2}$ & 0,150 & 0,150 & 0,150 & 0,150 & 0,150 \\
\hline Sal comum & 0,337 & 0,337 & 0,337 & 0,337 & 0,337 \\
\hline Avilamicina & 0,050 & 0,050 & 0,050 & 0,050 & 0,050 \\
\hline \multicolumn{6}{|l|}{ Composição calculada ${ }^{3}$} \\
\hline Proteína bruta (\%) & 13,67 & 13,67 & 13,67 & 13,67 & 13,67 \\
\hline EM (kcal/kg) & 3.262 & 3.262 & 3.262 & 3.262 & 3.262 \\
\hline Lisina total $(\%)$ & 0,823 & 0,823 & 0,823 & 0,823 & 0,823 \\
\hline Lisina digestível (\%) & 0,750 & 0,750 & 0,750 & 0,750 & 0,750 \\
\hline $\begin{array}{l}\text { Metionina+cistina } \\
\text { digestível }(\%)\end{array}$ & 0,504 & 0,504 & 0,504 & 0,504 & 0,504 \\
\hline $\begin{array}{l}\text { Treonina } \\
\text { digestível (\%) }\end{array}$ & 0,542 & 0,542 & 0,542 & 0,542 & 0,542 \\
\hline $\begin{array}{l}\text { Triptofano } \\
\text { digestível (\%) }\end{array}$ & 0,124 & 0,133 & 0,142 & 0,151 & 0,160 \\
\hline Cálcio $(\%)$ & 0,450 & 0,450 & 0,450 & 0,450 & 0,450 \\
\hline Fósforo disponível (\%) & 0,150 & 0,150 & 0,150 & 0,150 & 0,150 \\
\hline $\begin{array}{l}\text { Relação triptofano: } \\
\text { lisina digestível }\end{array}$ & 16,5 & 17,7 & 18,9 & 20,1 & 21,3 \\
\hline
\end{tabular}

${ }^{1}$ Conteúdo por kg: vit. A - 6.000.000 UI; vit. $D_{3}-1.500 .000 \mathrm{UI}$; vit. E 15.000.000 Ul; vit. $B_{1}-1,35$ g; vit. $B_{2}-4$ g; vit. $B_{6}-2$ g; ácido pantotênico $9,35 \mathrm{~g}$; vit. $\mathrm{K}_{3}-1,5 \mathrm{~g}$; ácido nicotínico - 20,0 g; vit. B12 - 20,0 g; ácido fólico - 0,6 g; biotina - $0,08 \mathrm{~g}$; I - 1,5 g; Se - 0,3 g; excipiente q. s. p. $1.000 \mathrm{~g}$.

2 Conteúdo por kg: Fe - 100 g; Cu - 10 g; Co - 1 g; Mn - 40 g; Zn - 100 g

excipiente q.s.p. - $1.000 \mathrm{~g}$.

${ }^{3}$ Composição calculada segundo Rostagno et al. (2005). 
Durante o período experimental, os animais receberam as rações e água à vontade. As rações e as sobras foram pesadas periodicamente, enquanto os animais foram pesados no início e ao final do período experimental para avaliação do ganho de peso e do consumo de ração. A conversão alimentar real foi obtida dividindo-se o consumo de ração total pelo ganho de peso dos animais de cada tratamento.

Ao final do período experimental, quando atingiram o peso de $125,0 \pm 3,31 \mathrm{~kg}$, os animais foram mantidos em jejum alimentar durante 18 horas. Posteriormente, foram pesados e abatidos em frigorífico localizado no município de Ponte Nova, Minas Gerais, por atordoamento elétrico e sangramento. Após o abate, os animais foram depilados com lançachamas e eviscerados. As carcaças foram submetidas a avaliação do rendimento de carne e da espessura de toucinho, conforme técnica adotada no frigorífico. As carcaças, excluindo cabeça e pés, foram pesadas para posterior cálculo do rendimento de carcaça.

Avaliaram-se o ganho de peso diário, consumo de ração diário, a conversão alimentar, o consumo de triptofano digestível diário, a espessura de toucinho no $\mathrm{P}_{2}$, o peso de carcaça, a quantidade de carne, a porcentagem de carne na carcaça e a taxa de deposição de carne.

As características de desempenho e de carcaça foram analisadas utilizando-se os procedimentos para análises de variância e de regressão, contidos no Sistema de Análises Estatísticas e Genéticas - SAEG, versão 8.0 (UFV, 2000). As estimativas de exigência de triptofano digestível e sua relação com a lisina digestível foram determinadas por meio de análises de regressão linear e quadrática.

\section{Resultados e Discussão}

Durante o período experimental, as temperaturas mínima e máxima no interior do galpão mantiveram-se em $12,5 \pm 1,3$ e $26,0 \pm 1,5^{\circ} \mathrm{C}$, respectivamente. A média da temperatura máxima ficou abaixo da temperatura crítica superior de $27^{\circ} \mathrm{C}$, estabelecida por Leal \& Nããs (1992) para suínos em terminação, o que caracterizou um ambiente de termoneutralidade.

Os níveis de triptofano influenciaram $(\mathrm{P}<0,06)$ o ganho de peso diário (Tabela 2) dos animais, que aumentou de forma quadrática até o nível estimado de $0,144 \%$, correspondente a uma relação de 19,2\% com a lisina digestível (Figura 1). Resultados semelhantes foram obtidos por Eder et al. (2003), que verificaram que o nível de $0,146 \%$ de triptofano digestível proporcionou o melhor ganho de peso dos suínos na fase de terminação ( 80 a $115 \mathrm{~kg}$ ). No entanto, Fremaut \& Deschrijver(1990), ao avaliarem níveis de triptofano com relação triptofano digestível:lisina digestível de 18,0 a $24,0 \%$, não observaram variação significativa no ganho de peso dos animais. Do mesmo modo, Haese et al. (2006) também não verificaram efeito significativo dos níveis de triptofano digestível $(0,128$ a $0,160 \%)$ sobre o ganho de peso diário de suínos machos castrados na fase dos 60 aos $95 \mathrm{~kg}$. Segundo esses autores, o nível de $0,128 \%$ triptofano

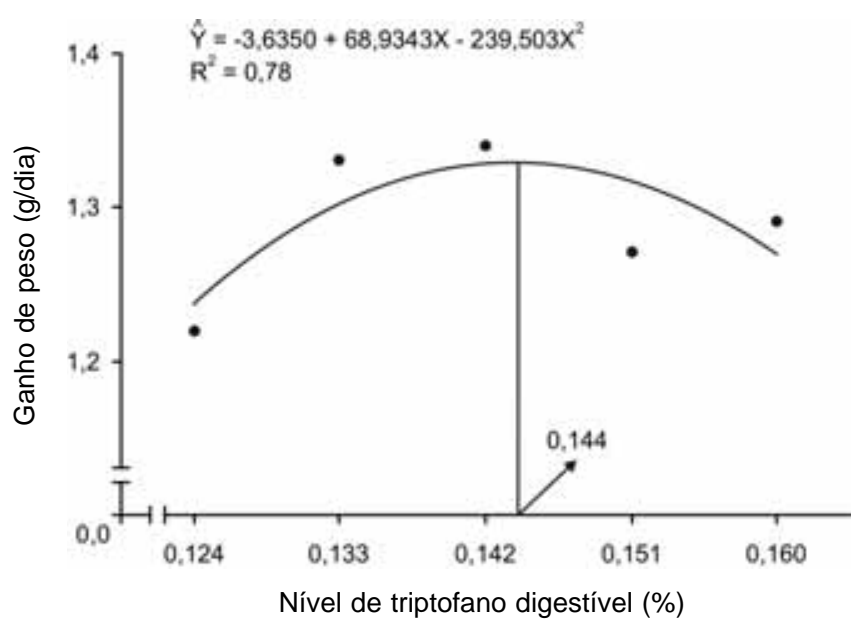

Figura 1 - Ganho de peso de suínos machos castrados de alto potencial genético na fase dos 97 aos $125 \mathrm{~kg}$ alimentados com rações contendo diversos níveis de triptofano digestível.

Tabela 2 - Desempenho de suínos machos castrados na fase dos 97 aos 125 kg alimentados com rações com diversos níveis de triptofano digestível

\begin{tabular}{|c|c|c|c|c|c|c|}
\hline \multirow[t]{2}{*}{ Característica } & \multicolumn{5}{|c|}{ Nível de triptofano digestível (\%) } & \multirow[t]{2}{*}{$\mathrm{CV}(\%)$} \\
\hline & 0,124 & 0,133 & 0,142 & 0,151 & 0,160 & \\
\hline Ganho de peso $(\mathrm{kg} / \mathrm{dia})^{1}$ & 1,22 & 1,33 & 1,34 & 1,27 & 1,29 & 10,05 \\
\hline Consumo de ração (kg/dia) & 3,68 & 3,76 & 3,89 & 3,68 & 3,71 & 7,73 \\
\hline Conversão alimentar $(\mathrm{kg} / \mathrm{kg})$ & 3,022 & 2,45 & 2,91 & 2,89 & 2,88 & 6,15 \\
\hline Consumo de triptofano $(\mathrm{g} / \mathrm{dia})^{2}$ & 4,56 & 5,00 & 5,52 & 5,56 & 5,94 & 7,67 \\
\hline
\end{tabular}

1 Efeito quadrático $(P<0,06)$.

2 Efeito linear $(P<0,01)$. 
digestível, correspondente à relação de 16,0\% com a lisina digestível, foi suficiente para atender às exigências para máximo crescimento dos animais.

A diferença entre o nível de triptofano encontrado neste estudo de $0,144 \%$ e o obtido por Haese et al. (2006), de $0,128 \%$, pode ser, em parte, justificada pela diferença no peso de abate dos animais. De acordo com Fuller (1991), a exigência de mantença dos animais aumenta de acordo com seu peso de abate, uma vez que o aumento da exigência de alguns aminoácidos relacionados à mantença dos animais, como o triptofano, é ocasionado pela associação desses aminoácidos com as perdas endógenas e a renovação celular da mucosa intestinal. Assim, a relação do triptofano com lisina aumenta conforme a exigência de mantença dos animais, visto que a lisina é utilizada, quase totalmente, para a deposição protéica.

O consumo de ração diário (CRD) não foi influenciado (P>0,10) pelos níveis de triptofano digestível. De forma semelhante, Hahn et al. (1995), Eder et al. (2003) e Guzik et al. (2005) também não constataram influência do aumento do nível de triptofano sobre o consumo de ração de suínos na fase de terminação. Burgoon et al. (1992) e Rossoni et al. (2003), no entanto, verificaram variação significativa no consumo de ração dos animais quando avaliaram níveis de triptofano em rações para suínos na fase de terminação.

A divergência de resultados quanto à influência do nível de triptofano sobre a ingestão voluntária de alimentos em suínos pode estar relacionada, entre outros fatores, a diferenças nas concentrações de triptofano e dos grandes aminoácidos neutros (AGN) - valina, leucina, isoleucina, tirosina e fenilalanina - nas rações experimentais.

De acordo com Henry et al. (1992), a baixa relação entre o triptofano e os AGN na ração e no plasma diminui a disponibilidade de triptofano no cérebro. Conseqüentemente, a produção de serotonina, um neurotransmissor que influencia o consumo de alimento, é também reduzida. Assim, o menor nível de triptofano digestível avaliado neste estudo $(0,124 \%)$ provavelmente não foi suficientemente baixo para comprometer a produção de serotonina no cérebro a ponto de influenciar significativamente o consumo diário de ração pelos animais.

Ainda com base nos resultados de consumo de ração, deduz-se que os animais não ajustaram o consumo de ração para atender à exigência de triptofano para máximo crescimento. Esse padrão de resposta difere do observado por Ferguson \& Gous (1997) e Ferguson et al. (2000a,b), que constataram que suínos em crescimento aumentam o consumo voluntário de alimentos quando alimentados com rações com baixos níveis de proteína bruta, treonina e lisina.
Não houve efeito $(\mathrm{P}>0,10)$ dos níveis de triptofano digestível sobre a conversão alimentar (CA) dos animais, apesar da melhora de 18,9\% nos valores absolutos de conversão alimentar quando o nível de triptofano na ração aumentou de 0,124 para $0,133 \%$. Esse resultado é indicativo de que o nível de $0,124 \%$ comprometeu a eficiência de utilização do alimento pelos animais.

De forma semelhante, Eder et al. (2003), estudando níveis de triptofano digestíveis em relações de 8,7 a 23,0\% com a lisina digestível para suínos de 80 a $115 \mathrm{~kg}$, não observaram variação na CA dos animais a partir da relação de $15,0 \%$ de triptofano digestível:lisina digestível. Conduzindo estudos com suínos dos 60 aos $95 \mathrm{~kg}$, Haese et al. (2006) também não constataram efeito significativo dos níveis de triptofano sobre a conversão alimentar dos animais. Guzik et al. (2005), no entanto, verificaram que a conversão alimentar dos suínos em terminação melhorou com a adição de triptofano nas rações e que a melhor resposta foi obtida no nível de $0,109 \%$ de triptofano digestível, correspondente a uma relação de $21,0 \%$ com a lisina digestível.

As variações na conversão alimentar relacionadas ao nível de triptofano das rações podem estar associadas a fatores como genética e sexo dos animais e à composição das rações experimentais.

Os níveis de triptofano digestível tiveram efeito $(\mathrm{P}<0,01)$ sobre o consumo de triptofano diário (CTD), que aumentou de forma linear, segundo a equação: $\hat{\mathrm{Y}}=0,3156+36,1837 \mathrm{X}\left(\mathrm{r}^{2}=0,91\right)$. A relação positiva entre o consumo de triptofano diário e o nível desse aminoácido na ração pode estar relacionada à ausência de variação no consumo diário de ração entre os animais alimentados com as diversas rações.

O nível de triptofano digestível $(0,144 \%)$ que proporcionou o melhor resultado de desempenho dos animais neste estudo ficou acima dos níveis de 0,090 e 0,096\%, observados, respectivamente, por Burgoon et al. (1992) e Guzik et al. (2005), para suínos em terminação, e dos níveis de 0,100 e $0,126 \%$ preconizados, respectivamente, pelo NRC (1998) e por Rostagno et al. (2005) para suínos machos castrados dos 100 aos $120 \mathrm{~kg}$.

Embora os níveis propostos no NRC (1998) e em Rostagno et al. (2005) sejam significativamente menores que o obtido neste estudo, constatou-se que, quando se considerou a relação triptofano:lisina digestíveis, os valores foram similares em 19\%. Assim, pode-se inferir que o nível de lisina digestível das rações experimentais é um dos fatores que contribuem para a variação nos resultados entre os trabalhos. 
Além do nível de lisina, outros fatores, como o ambiente térmico, o status imunológico e a genética dos animais, também podem contribuir para as diferenças entre resultados.

Avaliando a influência da temperatura ambiental sobre a resposta de suínos em crescimento ao nível de triptofano da ração, Ferguson \& Gous (2002) verificaram que o nível de triptofano que proporcionou o melhor desempenho dos animais variou de acordo com a temperatura ambiente.

Em abordagem sobre o desafio imunológico, Le Floc'h et al. (2004) e Melchior et al. (2004) propuseram que as exigências de alguns aminoácidos, entre eles o triptofano, fossem aumentadas durante a estimulação do sistema imune dos animais. Thong \& Liebert (2004), por sua vez, relataram que a deposição de proteína é determinante da exigência de aminoácidos em suínos.

Não houve influência $(\mathrm{P}>0,10)$ dos níveis de triptofano digestível da ração sobre as características de carcaça avaliadas (Tabela 3). De forma similar, Fremaut \& Deschrijver (1990), Henry et al. (1992) e Haese et al. (2006) não verificaram variação significativa na espessura de toucinho e na porcentagem de carne na carcaça de suínos em terminação quando aumentaram o nível de triptofano da ração. Henry (1995), no entanto, constatou, para suínos de 55 a $88 \mathrm{~kg}$ abatidos em mesma idade, efeito dos níveis de triptofano $(0,10$ vs $0,13 \%)$ sobre as deposições de tecido magro e adiposo, que diminuíram com a deficiência de triptofano na ração. Todavia, quando os animais foram abatidos com mesmo peso corporal, não houve influência dos níveis de triptofano da ração sobre a composição de carcaça.

Considerando estes relatos, pode-se inferir que o abate com mesmo peso, associado à pequena variação nos níveis de triptofano avaliados, contribuiu para que não houvesse diferença nas características de carcaça avaliadas.

Tabela 3 - Características de carcaça de suínos machos castrados dos 97 aos $125 \mathrm{~kg}$ alimentados com rações contendo diversos níveis de triptofano digestível

\begin{tabular}{|c|c|c|c|c|c|c|}
\hline \multirow[t]{2}{*}{ Característica } & \multicolumn{5}{|c|}{ Nível de triptofano digestível (\%) } & \multirow[t]{2}{*}{$\mathrm{CV}(\%)$} \\
\hline & 0,124 & 0,133 & 0,142 & 0,151 & 0,160 & \\
\hline Espessura toucinho (mm) & 18,24 & 19,44 & 18,03 & 17,52 & 17,42 & 28,29 \\
\hline Peso de carcaça $(\mathrm{kg})$ & 87,70 & 89,02 & 87,79 & 87,77 & 88,49 & 3,32 \\
\hline Quantidade de carne $(\mathrm{kg})$ & 48,34 & 49,59 & 48,50 & 49,06 & 49,74 & 4,52 \\
\hline Percentual de carne $(\%)$ & 55,15 & 55,71 & 55,28 & 55,92 & 56,19 & 4,29 \\
\hline Deposição de carne (g/dia) & 474 & 511 & 451 & 497 & 504 & 19,80 \\
\hline
\end{tabular}

\section{Conclusões}

O nível estimado de $0,144 \%$ de triptofano digestível, correspondente a uma relação de $19,2 \%$ com a lisina digestível, proporciona melhor ganho de peso para suínos machos castrados de alto potencial genético na fase dos 97,0 aos $125,0 \mathrm{~kg}$.

\section{Literatura Citada}

BAKER, D.H.; CHUNG, T.K. Ideal protein for swine and poultry. Chesterfield: Biokyowa Inc., 1992. p.1-13. (Biokyowa Technical. Review 4).

BURGOON, K.G.; KNABE, D.A.; GREGG, E.J. Digestible tryptophan requirements of starting, growing, and finishing pigs. Journal of Animal Science, v.70, p.2493-2500, 1992.

EDER, K.; NONN, H.; KLUGE, H. et al. Tryptophan requirement of growing pigs at various body weights. Journal Animal Phisiology and Animal Nutrition, v.87, p.336-346, 2003.

FERGUSON, N.S.; GOUS, R.M. The influence of heat production on voluntary food intake in growing pigs given proteindeficient diets. Animal Science, v.64, p.365-378, 1997.
FERGUSON, N.S.; ARNOLD, G.A.; LAVERS, G. et al. The response of growing pigs to amino acids as influenced by environmental temperature. 1. Threonine. Animal Science, v.70, p.287-297, $2000 \mathrm{a}$.

FERGUSON, N.S.; ARNOLD, G.A.; LAVERS, G. et al. The response of growing pigs to amino acids as influenced by environmental temperature. 2. Lysine. Animal Science, v.70, p.299-306, $2000 \mathrm{~b}$.

FERGUSON, N.S.; GOUS, R.M. The response of growing pigs to amino acids as influenced by environmental temperature: tryptophan. Animal Science, v.74, p.103-110, 2002.

FREMAUT, D.; DESCHRIJVER, R. Tryptophan supplementation of diets for growing-finishing pigs. Revue de I'Agriculture, v.43, p.761-768, 1990.

FULLER, M.F. Present knowledge of amino acid requirements for maintenance and production. In: EGGUM, B.O.; BOISEN, S.; BØRSTING, C. et al. (Eds.) Protein metabolism and nutrition. Herning: 1991. p.116. (EAAP Publication, 59).

FULLER, M.F. Macronutrients requirements of growing swine. In: SIMPÓSIO INTERNACIONAL SOBRE EXIGÊNCIAS NUTRICIONAIS DE AVES E SUÍNOS, 1., 1996, Viçosa, MG. Anais... Viçosa, MG: Universidade Federal de Viçosa, 1996. p.205-221.

GUZIK, A.C.; SHELTON, J.L.; SOUTHERN, L.L. et al. The tryptophan requirement of growing and finishing barrows. Journal of Animal Science, v.83, p.1303-1311, 2005. 
HAESE, D.; DONZELE, J.L.; OLIVEIRA, R.F.M. et al. Níveis de triptofano digestível em rações para suínos machos castrados de alto potencial de deposição de carne magra na carcaça dos 60 aos $95 \mathrm{~kg}$. Revista Brasileira de Zootecnia, v.35, p.23092313,2006

HAHN, J.D.; BIEHL, R.R.; BAKER, D. Ideal digestible lysine level for early and late finishing swine. Journal of Animal Science, v.73, p.773-784, 1995.

HENRY, Y.; SÈVE, B.; COLLÉAUX, Y. et al. Interactive effects of dietary levels of tryptophan and protein on voluntary feed intake an growth performance in pigs, in relation to plasma free amino acids and hypothalamic serotonin. Journal of Animal Science, v.70, p.1873-1887, 1992.

HENRY, Y. Effects of dietary tryptophan deficiency in finishing pigs, according to age or weight at slaughter or live weight gain. Livestock Production Science, v.41, p.63-76, 1995.

LEAL, P.M.; NÃ̃̃̃S, I.A. Ambiência animal. In: CORTES, L.A.B.; MAGALHÃES, P.S.G. (Eds.). Introdução à engenharia agrícola. Campinas: Unicamp, 1992. p.121-135.

LE FLOC'H, N.; MELCHIOR, D.; OBLED, C. Modifications of protein and amino acid metabolism during inflammation and immune system activation. Livestock Production Science, v.87, p.37-45, 2004.
MELCHIOR, D.; SÉVE, B.; LE FLOC'H, N. Chronic lung inflammation affects plasma amino acid concentrations in pigs. Journal of Animal Science, v. 82, p.1991-1099, 2004.

NATIONAL RESEARCH COUNCIL - NRC. Nutritional requirements of swine. 10.ed. Washington, D.C.: National Academic Science, 1998. $189 \mathrm{p}$.

ROSSONI, M.C.; DONZELE, J.L.; SILVA, F.C.O. et al. Avaliação de diferentes relações triptofano:lisina digestíveis em rações para suínos machos castrados dos 60 aos $95 \mathrm{~kg}$. In: CONGRESSO BRASILEIRO DE VETERINÁRIOS ESPECIALISTAS EM SUÍNOS, 11., 2003, Goiânia. Anais... Goiânia: 2003. p.35-54.

ROSTAGNO, H.S.; ALBINO, L.F.T.; DONZELE, J.L. et al. Tabelas brasileiras para aves e suínos: composição de alimentos e exigências nutricionais. Viçosa, MG: Universidade Federal de Viçosa, 2005. p.141.

THONG, H.T.; LIEBERT, F. Potential of protein deposition and threonine requirement of modern genotype barrows fef graded levels of protein with threonine as the limiting amino acid. Journal Animal Physiology and Animal Nutrition, v. 88 , p. 196-203, 2004

UNIVERSIDADE FEDERAL DE VIÇOSA - UFV. SAEG - Sistemas de análises Estatísticas e Genéticas. (Versão 8.0). Viçosa, MG: 2000. (CD-ROM). 